\title{
A NOTE ON MY PAPER ON A RESULT OF G. D. BIRKHOFF ON LINEAR DIFFERENTIAL SYSTEMS
}

P. MASANI

The incorrectness of Birkhoff's result, with which the paper [2] is concerned, was noted already by F. R. Gantmacher in 1954 in his book Theory of matrices (Russian); cf. the recent English translation of the second part of this, [1, pp. 175-176]. Example $C$ in [2] is, in fact, the analogue of Gantmacher's counter-example when $z=\infty$ is taken instead of $z=0$ as the singular point. Gantmacher does not, however, discuss the cases in which the result is correct; cf. [2, D].

Unfortunately, the writer became aware of Gantmacher's work only when it was too late to have paper [2] withdrawn or even to have a note added to it.

\section{REFERENCES}

1. F. R. Gantmacher, Application of the theory of matrices, New York, 1959.

2. P. Masani, On a result of $G$. D. Birkhoff on linear differential systems, Proc. Amer. Math. Soc. vol. 10 (1959) pp. 696-698.

Received November 5, 1959.

Brown UNIVERSITY 